
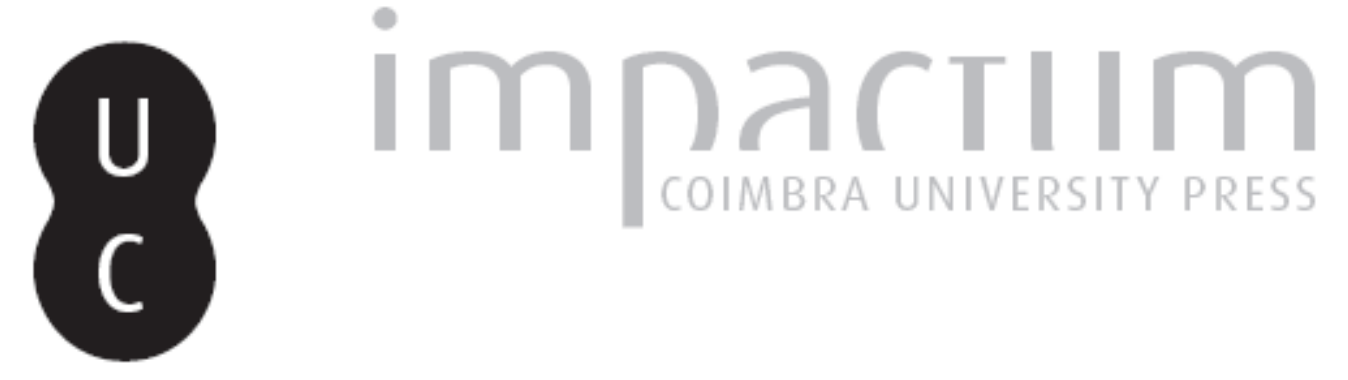

\title{
Riscos para a saúde das populações: estudo de caso do electromagnetismo no município de Guimarães
}

Autor(es): $\quad$ Azevedo, Bruno; Remoaldo, Paula Cristina; Nogueira, Helena

Publicado por: Associação Portuguesa de Riscos, Prevenção e Segurança

URL

persistente:

URI:http://hdl.handle.net/10316.2/35947

DOI:

DOI:http://dx.doi.org/10.14195/1647-7723_19_16

Accessed : $\quad$ 26-Apr-2023 14:48:01

A navegação consulta e descarregamento dos títulos inseridos nas Bibliotecas Digitais UC Digitalis, UC Pombalina e UC Impactum, pressupõem a aceitação plena e sem reservas dos Termos e Condições de Uso destas Bibliotecas Digitais, disponíveis em https://digitalis.uc.pt/pt-pt/termos.

Conforme exposto nos referidos Termos e Condições de Uso, o descarregamento de títulos de acesso restrito requer uma licença válida de autorização devendo o utilizador aceder ao(s) documento(s) a partir de um endereço de IP da instituição detentora da supramencionada licença.

Ao utilizador é apenas permitido o descarregamento para uso pessoal, pelo que o emprego do(s) título(s) descarregado(s) para outro fim, designadamente comercial, carece de autorização do respetivo autor ou editor da obra.

Na medida em que todas as obras da UC Digitalis se encontram protegidas pelo Código do Direito de Autor e Direitos Conexos e demais legislação aplicável, toda a cópia, parcial ou total, deste documento, nos casos em que é legalmente admitida, deverá conter ou fazer-se acompanhar por este aviso.

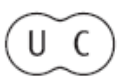




\section{territorium}

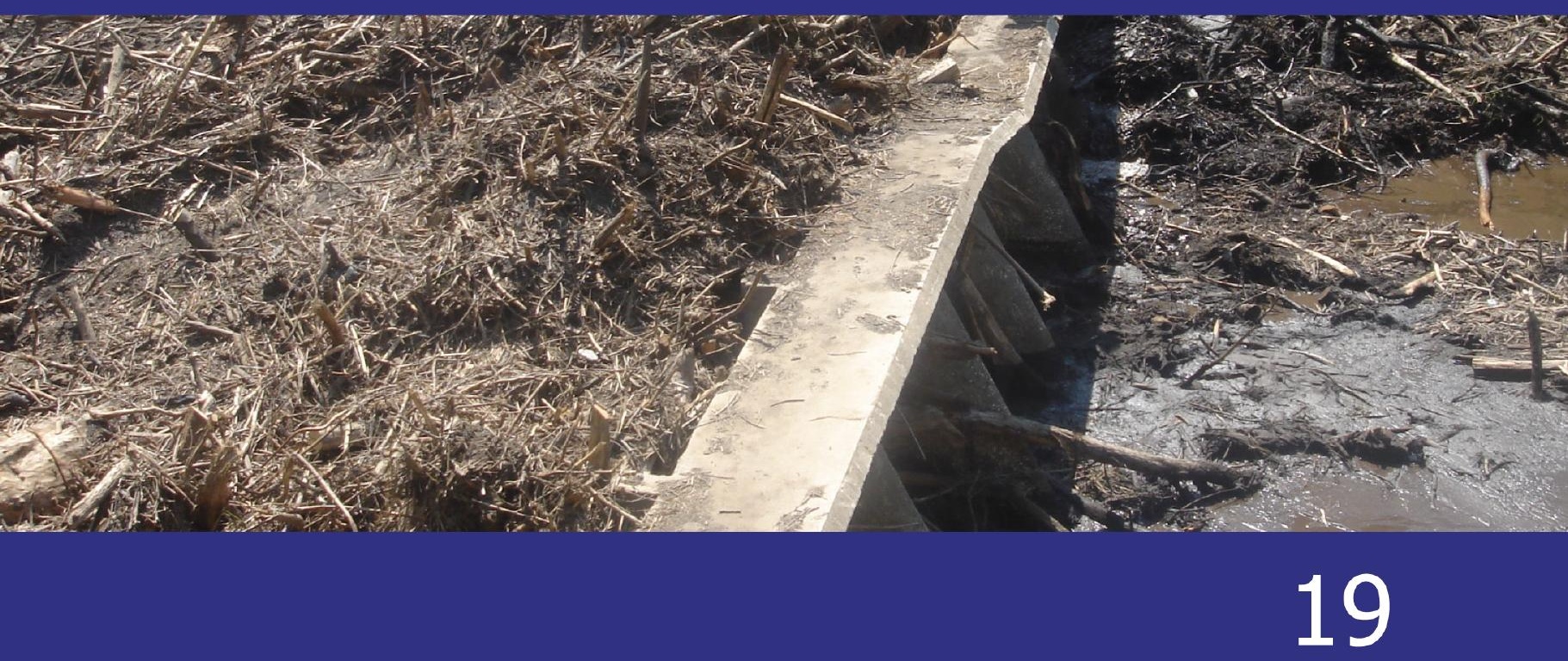

\section{Reequacionar o Conhecimento dos Riscos e das Catástrofes}

Revista da Associação Portuguesa de Riscos, Prevenção e Segurança 


\section{RISCOS PARA A SAÚDE DAS POPULAÇÕES - ESTUDO DE CASO DO ELECTROMAGNETISMO NO MUNICÍPIO DE GUIMARÃES*}

Bruno Azevedo

Geografia, área de Especialização em Planeamento e Gestão do Território Brunoflipe12@yahoo.com

Paula Cristina Remoaldo

Departamento de Geografia da Universidade do Minho premoaldo@geografia.uminho.pt

Helena Nogueira

Departamento de Geografia da Universidade de Coimbra helenamarquesnogueira@gmail.com

\section{RESUMO}

No presente artigo os autores realizam uma primeira aproximação de uma investigação em curso relacionada com o tipo de impacto dos postes e das linhas de alta e muito alta tensão na saúde da população, centrando-se na freguesia de Serzedelo (município de Guimarães), devido à elevada densidade deste tipo de postes e linhas e porque a freguesia foi estudada sumariamente ao nível da mortalidade pela Autoridade Regional de Saúde do Norte. Na presente investigação é ensaiada uma nova metodologia (estudo de expostos e não expostos), apresentando as respectivas limitações e vantagens.

Palavras chave: Campos electromagnéticos, riscos, saúde, Guimarães.

\section{RESUMEN}

Riesgos por la salud de la población - estudio de caso del electromagnetismo en Guimarães - En este artículo los autores proporcionan una primera aproximación a una investigación en curso relacionada con el tipo de impacto de los postes y las líneas de alta y muy alta tensión en la salud de la población, centrándose en la parroquia de Serzedelo (municipio de Guimarães), debido la alta densidad de este tipo de postes y líneas, ya que la parroquia se ha estudiado brevemente en relación con la mortalidad por la Autoridad Regional de Salud del Norte. En la presente investigación se prueba una nueva metodología (estudio de los expuestos y no expuestos), presentando sus limitaciones y ventajas.

Palabras clave: Campos electromagnéticos, riesgos, salud, Guimarães.

\section{RÉSUMÉ}

Risques pour la santé de la population - étude de cas de l'électromagnétisme à Guimarães - Dans ce travail les auteurs présentent quelques réflexions d'une recherche en cours qui concerne l'évaluation de l'impact des lignes de haute et très haute tension dans la santé des populations. La recherche évalue l'impact dans la paroisse de Guimarães (municipalité de Guimarães dans le nord-ouest du Portugal), parce que cette paroisse a une haute densité de ces types de lignes et parce que cette problématique a été étudiée très sommairement par les autorités publiques. Les auteurs testent une nouvelle méthodologie (étude des exposés et non exposés) en expliquant ses avantages et limitations.

Mots-clé: Champs électromagnétiques, risque, santé, Guimarães.

\section{ABSTRACT}

Risks for population health - case study of electromagnetism in Guimarães - In this paper the authors present a first effort to understand the impact of poles and lines of very high voltage in health population, mainly in Serzedelo parish (municipality of Guimarães in the Northwest of Portugal). Serzedelo was selected because of the high density of this kind of poles and lines and because it was studied only summarily by public authorities. In present investigation we test a new methodology (study of exposed and unexposed) explaining its advantages and limitations.

Key words: Electromagnetic fields, risk, health, Guimarães.

* O texto deste artigo corresponde à comunicação apresentada ao II Congresso Internacional de Riscos e VI Encontro Nacional, tendo sido submetido para revisão em 04-09-2010, tendo sido aceite para publicação em 01-04-2011.

Este artigo é parte integrante da Revista Territorium, n. ${ }^{\circ} 19,2012,{ }^{\circ}$ RIscos, ISBN: 0872- 8941. 


\section{Introdução}

Duas das mais importantes descobertas da Humanidade foram os princípios e as leis do electromagnetismo, que permitiram a utilização da electricidade. Foi a partir do século XVI que o fenómeno da electricidade sofreu vários desenvolvimentos que permitiram abrir caminho à Revolução Industrial, sendo essencial para o funcionamento das indústrias e para o desenvolvimento da maquinaria em detrimento do trabalho artesanal.

Paralelamente, o desenvolvimento (económico, tecnológico e demográfico) das nações veio aumentar as necessidades e o consumo de energia eléctrica. Podemos ainda associar-lhe uma mudança nos hábitos quotidianos das populações, que consistiu na criação de vários equipamentos, de que se destacam os electrodomésticos, que tinham e têm o intuito de facilitar algumas tarefas do nosso dia-a-dia e de aumentar os nossos níveis de conforto e de qualidade de vida. A electricidade passou a ser transportada para as povoações por cabos de várias tensões (baixa, média, alta e muito alta tensão), e com o aumento das necessidades de consumo começaram a proliferar as linhas e postes de alta tensão, existindo mesmo alguns lugares, mais concretamente os que estão próximos de subestações, onde a concentração dos mesmos é muito elevada.

A poluição electromagnética é um tipo de poluição que não pára de aumentar. Esta poluição invisível pode ter efeitos nefastos na saúde das populações, especialmente ao nível das doenças crónicodegenerativas (e.g., cancros e mais especificamente, as leucemias infantis).

A partir de Outubro de 2009, optámos por investigar a freguesia de Serzedelo, do município de Guimarães, por este território possuir uma elevada concentração de postes e linhas de alta e muita alta tensão, e por ter nas suas proximidades a subestação eléctrica de Riba de Ave (município de Vila Nova de Famalicão), que é uma das unidades com mais elevada potência a nível nacional.

No que diz respeito à problemática, a questão de partida foi a seguinte: De que forma a escolha do lugar de residência pode influenciar o estado (historial) de saúde e ou de doença dos indivíduos? Tendo por base esta questão ainda pretendemos aprofundar a nossa investigação, tentando responder à seguinte: Até que ponto a proximidade (até 50 metros) das linhas de alta e muito alta tensão pode afectar a saúde e bem-estar dos indivíduos?

No que concerne aos objectivos, equacionámos atingir os seguintes:

- Aferir o tipo de impacto dos postes e das linhas de alta e muito alta tensão na saúde da população de Serzedelo;
- Comparar a saúde da população de Serzedelo que habita na proximidade das linhas e dos postes de alta e muito alta tensão (até 50 metros) com a saúde dos que habitam a uma distância a partir dos 250 metros;

- Propor um plano de actuação para o município de Guimarães, mais concretamente para as áreas residenciais sensíveis (caso de Serzedelo).

Ao nível da metodologia utilizada, optámos por realizar inquéritos por entrevista semi-estruturada à população de Serzedelo, a dois grupos populacionais distintos: o grupo dos expostos e o dos não expostos. Fazem parte do grupo dos expostos todos os indivíduos que habitam nas proximidades (até 50 metros) das linhas e postes de alta e muito alta tensão. Os que residem a 250 e mais metros das referidas linhas foram considerados como pertencentes ao grupo dos não expostos.

0 presente artigo constitui o primeiro ensaio de sistematização do trabalho realizado até ao momento, centrando-se nos estudos concretizados nos últimos trinta anos à escala internacional e numa metodologia que não foi ainda concretizada para o município de Guimarães. Pretende insistir no facto do geógrafo ser um cientista social que pode complementar os estudos realizados até ao momento por outro tipo de cientistas que manifestam dificuldades em incorporar a vertente territorial.

Assim, no presente artigo, começamos por nos debruçar sobre o conceito de risco, bem como as principais influências dos campos electromagnéticos no corpo humano e na saúde dos indivíduos. Continuamos, com uma breve caracterização da morbilidade na região Norte e no município de Guimarães. Prosseguimos com a caracterização da metodologia utilizada e das dificuldades encontradas até ao momento, avançando com alguns resultados estatísticos simples, relativos à amostra recolhida. Trata-se de resultados que correspondem ainda a uma descrição da amostra, mas que são fundamentais para uma análise mais aprofundada, que pretendemos efectuar por intermédio de regressões logísticas. A utilização destas regressões assume particular importância uma vez que, conduzindo à obtenção das probabilidades relativas (Odds Ratios), permitirão estimar diferenças na saúde individual em função de diferenças no grau de exposição. Terminamos o artigo apresentando algumas sugestões que poderão servir para futuros estudos.

\section{Campos electromagnéticos de baixa frequência e sua influência na saúde das populações}

\section{Risco Tecnológico}

Ao falarmos de campos electromagnéticos, sobretudo os campos electromagnéticos emitidos (ou produzidos) 
pelas linhas eléctricas de alta e muito alta tensão e os seus possíveis efeitos na saúde dos indivíduos que habitam próximo dessas linhas, estamos a referirmonos a um risco para a saúde das populações. Segundo L. Faugères (1990), risco é um sistema complexo de processos, cuja modificação do funcionamento é susceptível de produzir danos directos ou indirectos numa determinada população.

Numa perspectiva epidemiológica, um risco corresponde à probabilidade de ocorrência de uma enfermidade ou morte numa determinada população (H. NogUeIRA; P. Remoaldo, 2010).

Quanto à tipologia, os campos electromagnéticos emitidos pelas linhas eléctricas de alta e muito alta tensão devem ser classificados como sendo um risco antrópico, pois estamos perante um fenómeno que tem origens na acção humana.

Dentro deste grande grupo de riscos que são os antrópicos, ainda podemos classificar os campos electromagnéticos emitidos pelas linhas de alta e muito alta tensão como sendo um risco tecnológico. Este último ocorre quando existe uma desconsideração das regras e da harmonia ou equilíbrio que deve existir entre as tecnologias (ou produtos perigosos) e as comunidades e o meio ambiente.

Este elemento, os campos electromagnéticos, que inicialmente pareciam desprovidos de malefícios, tornaram-se recentemente num risco com uma relevante importância para a nossa saúde. A própria Organização Mundial de Saúde (OMS) iniciou, a partir de 1996, o "Projecto Internacional dos Campos Electromagnéticos", pretendendo analisar todos os estudos realizados, promover mais investigação credível, bem como facultar informação para que as populações possam ter em consideração este risco e assim poderem diminuir a exposição aos campos electromagnéticos.

\section{Sistemas eléctricos}

A energia eléctrica é considerada actualmente um bem de primeira necessidade, essencial no nosso dia-a-dia, bem como para o funcionamento e desenvolvimento da maioria das actividades económicas. A massificação da utilização da energia eléctrica levou ao aumento do consumo da mesma e consequentemente a um desenvolvimento dos sistemas eléctricos de todos os países, com especial relevância para a evolução das redes de transporte e de distribuição de energia eléctrica.

A rede de distribuição de energia eléctrica integra todas as linhas de média e baixa tensão e tem como principal função abastecer as habitações e as indústrias, sendo também utilizada na iluminação pública. Por outro lado, a rede de transporte de energia eléctrica é constituída por linhas eléctricas de alta e muito alta tensão e o seu objectivo principal é transportar a energia entre as unidades de produção e as unidades de redistribuição (subestações).

As principais diferenças entre a energia transportada pela rede de distribuição e a rede de transporte é a tensão (potência) a que a electricidade é transportada. Como o principal objectivo da rede de distribuição é transportar energia eléctrica para ser consumida por pessoas ou indústrias, a potência da energia transportada costuma ser baixa ou média.

\section{Radiações não ionizantes e o comportamento dos campos electromagnéticos}

Sinteticamente, podemos afirmar que todos os tipos de radiação que compõem o espectro electromagnético são agrupados em dois grandes grupos, as radiações ionizantes e as não ionizantes.

As radiações ionizantes caracterizam-se pela sua elevada frequência e pela sua capacidade de causar danos graves e permanentes no corpo humano, quebrando as relações e as ligações atómicas que mantêm as moléculas junto das células, danificando-as e, assim, prejudicando a saúde dos indivíduos que estão expostos a este tipo de fonte de radiação (P. DÉoux; S. DÉoux,1996).

Por outro lado, temos as radiações não ionizantes, que englobam todas as fontes de radiação que não contêm energia suficiente para quebrar ligações atómicas (OMS, 1998). Todavia, segundo alguns autores (e.g., P. DÉoux; S. DÉoux, 1996), a designação não ionizante, inicialmente parecia significar que este tipo de radiação estava desprovido de risco para a saúde dos indivíduos, mas tem evidenciado influência no binómio saúde-doença, a julgar pelos vários estudos realizados desde 1979.

As linhas eléctricas de alta e muito alta tensão, que são centrais na nossa investigação, são, assim, uma fonte de radiação não ionizante e de extremamente baixa frequência, também designada por EBF (P. Déoux; S. DÉoux,1996; OMS, 1998, 2007).

A capacidade e o tipo de interacção entre os campos electromagnéticos e os organismos humanos são determinados por dois factores: a frequência da fonte de radiação electromagnética e a intensidade dos referidos campos electromagnéticos.

Numa primeira análise, podemos referir que, como estamos perante uma fonte de radiação não ionizante a baixas frequências, a sua capacidade de interacção com os organismos vivos deve ser reduzida. Contudo, o transporte da energia eléctrica é efectuado a altas tensões e vai levar à emissão de campos electromagnéticos com valores bastante elevados que podem ter consequências 
na saúde das pessoas que habitem nas proximidades das referidas linhas de alta tensão.

O campo eléctrico e o campo magnético têm comportamentos diferentes quando estão em contacto com os organismos vivos. A penetração de campos eléctricos exógenos ao corpo humano é quase totalmente atenuada pelas propriedades da pele, funcionando como uma blindagem contra a entrada desses campos, enquanto para os campos magnéticos o corpo humano não oferece resistência, visto que os campos magnéticos só não conseguem atravessar o ferro (J. SÁ, 2008).

FaradaY descobriu que um campo magnético que varia no tempo e no espaço pode induzir um campo eléctrico, e como o corpo humano não tem permeabilidade magnética, ao ser atravessado por um campo magnético, este pode gerar campos eléctricos no interior do corpo, a que se associam correntes que parecem constituir um problema, causando efeitos nefastos (e.g., leucemias, linfomas) nos seres vivos em geral e no indivíduo em particular (P. DÉoux; $S$. DÉoux,1996; OMS, 1998; J. SÁ, 2008).

A diferença de comportamento entre os campos magnéticos e eléctricos quando entram em contacto com o corpo humano, associada às conclusões de inúmeros estudos epidemiológicos, que levantavam a possibilidade da relação entre os campos electromagnéticos a EBF e o aumento do risco e dos casos de cancro levou a Internacional Agency for Research on Cancer (IARC), em 2002, a classificar os campos magnéticos da corrente eléctrica como possivelmente carcinogénicos para seres humanos. Anteriormente, em 1998, a congénere norteamericana National Institute for Environmental Health Sciences (NIEHS) tinha tirado a mesma conclusão.

A classificação do IARC significa que foi reportada pelos vários estudos epidemiológicos uma associação positiva entre o aumento do risco de cancro e os campos magnéticos a EBF.

\section{Principais estudos sobre a interacção dos campos electromagnéticos e o corpo humano}

Porque é que o corpo humano é sensível às ondas electromagnéticas (ou campos electromagnéticos)? É sensível porque o funcionamento, a regulação e a “comunicação" entre os complexos mecanismos de regulação fisiológica, como a actividade neuromuscular, a secreção glandular e o funcionamento da membrana celular são feitos por correntes endógenas ou processos electrofisiológicos (P. DÉoux; S. DÉoux, 1996). Portanto, se é evidente que o funcionamento e a regulação do nosso organismo é efectuado por processos eléctricos, é também credível que os campos electromagnéticos externos, quer naturais ou artificiais possam interferir nos processos electrofisiológicos.
Foi a partir do estudo efectuado por WeRTHEMEIR e LeEPER em 1979, nos Estados Unidos da América (EUA), que a problemática dos efeitos na saúde das linhas de alta tensão ganhou um novo élan em termos de investigação científica (QuAdro I). O estudo de WerThermeir e LeEPER (1979) verificou que existia um maior número de casos de leucemia nas crianças que habitavam próximo das linhas de alta tensão, concluindo então pela relação/ associação entre a proximidade às linhas de alta tensão e o aumento do risco de incidência de leucemia infantil.

Os EUA foram pioneiros nos estudos epidemiológicos e nas preocupações que começavam a surgir em torno dos efeitos dos campos electromagnéticos. Inúmeros estudos surgiram depois de 1979, podendo ser realçados os seguintes: SAVITZ et al., em 1988 (EUA), London et al., em 1991 (EUA), MARTHA LINET et al., em 1997 (EUA) e MCBRIDE, em 1999, no Canadá (J. Sá, 2008).

$\mathrm{Na}$ Europa os primeiros e principais estudos foram efectuados nos países do Norte. Destacam-se, o de Feychting e Alhbom, em 1993 (Suécia), o de Olsen, Nielsen e Shulgen, também em 1999 (Dinamarca), o de Tynes e HALDORSEN, em 1997 (Noruega), e, por fim, o de Schuz et al., em 2001 na Alemanha (J. SÁ, 2008).

O QuAdro I destaca alguns dos principais trabalhos que levaram o IARC, em 2002, a classificar os campos magnéticos como sendo possivelmente cancerígenos. De realçar que, embora tivessem sido efectuados diversos estudos em vários países, metodologicamente estes assentavam num pressuposto comum, o estudo de caso-controlo.

Ao nível da metodologia, os principais estudos efectuados e os presentes no QUADRo I, privilegiaram duas distintas técnicas: a proximidade magnética (Wire Codes), e a medição dos campos electromagnéticos.

A proximidade magnética consiste na tentativa de estimar os valores dos campos electromagnéticos, sabendo que a intensidade dos campos diminui em função da distância da fonte, ou seja, quanto mais perto mais intensos são os campos e vice-versa. A medição dos campos electromagnéticos consistia na medição dos campos junto às habitações das pessoas que viviam nas proximidades das linhas e ou que tinham alguma patologia, tentado assim verificar se existia alguma relação/associação entre certos valores dos campos e o aumento da incidência de algumas doenças.

Ao longo dos tempos, os métodos foram evoluindo e ficando cada vez mais precisos. Contudo, todos estes estudos sofreram críticas mais ou menos veementes. Na opinião da OMS, as críticas principais estão relacionadas com: a inconsistência e a incerteza dos resultados/conclusões; as amostras analisadas serem muito pequenas, pois as doenças associadas a esta problemática são raras. 
QUADRo I - Estudos realizados desde a década de setenta do século XX e conclusões encontradas.

\begin{tabular}{|c|c|c|c|c|}
\hline Ano & Autores & Tipo de Estudo & População estudada & Conclusões \\
\hline 1979 & WERTHEMEIR e LeEPER & $\begin{array}{l}\text { Wire-codes ou } \\
\text { Proximidade magnética. }\end{array}$ & $\begin{array}{l}\text { Todas as crianças } \\
\text { falecidas no Colorado } \\
\text { com leucemia infantil } \\
\text { (1950 e 1969) (E.U.A.). }\end{array}$ & $\begin{array}{l}\text { Aumento do risco de } \\
\text { incidência de leucemia } \\
\text { infantil. }\end{array}$ \\
\hline 1993 & FEYCHTING e AнLBOM & $\begin{array}{l}\text { Proximidade magnética } \\
\text { (amostra pequena). }\end{array}$ & $\begin{array}{l}\text { Crianças menores de } \\
16 \text { anos que tivessem } \\
\text { vivido a menos de } 300 \\
\text { metros de linhas de } \\
\text { alta tensão (Suécia). }\end{array}$ & $\begin{array}{l}\text { Duplicação da incidência } \\
\text { de leucemia infantil, } \\
\text { para campos magnéticos } \\
\text { superiores a } 0,1 \mu \mathrm{t} \text {. }\end{array}$ \\
\hline 1999 & MCBRIDE et al. & $\begin{array}{l}\text { Dois Estudos } \\
\text { 1-Wire codes } \\
\text { 2-Medições dos campos }\end{array}$ & $\begin{array}{l}1990 \text { e } 1994 \text { em } 5 \\
\text { províncias próximas } \\
\text { de cidades no Quebec } \\
\text { e Colómbia Britânica } \\
\text { (Canadá). }\end{array}$ & $\begin{array}{l}\text { Falta de correlação entre } \\
\text { campos magnéticos e } \\
\text { leucemia infantil. }\end{array}$ \\
\hline 1999 & $\begin{array}{l}\text { UK Childhood Cancer } \\
\text { Study Investigators }\end{array}$ & Proximidade Magnética. & $\begin{array}{l}\text { Todo o Reino Unido } \\
\text { excepto a Irlanda do } \\
\text { Norte. }\end{array}$ & $\begin{array}{l}\text { Ausência de relação entre } \\
\text { campos } \\
\text { magnéticos e leucemia } \\
\text { infantil. }\end{array}$ \\
\hline 2005 & DRAPER et al. & $\begin{array}{l}\text { Distância (metodologia } \\
\text { mais geográfica). }\end{array}$ & $\begin{array}{l}59 \text { milhões de habitantes } \\
\text { (Inglaterra, País de } \\
\text { Gales e Escócia). }\end{array}$ & $\begin{array}{l}\text { Associação entre a } \\
\text { proximidade às linhas e o } \\
\text { aumento da incidência. } \\
\text { Existirá uma relação, mas } \\
\text { não é de causa-éfeito. }\end{array}$ \\
\hline
\end{tabular}

Fonte: Elaboração própria com base em J. SÁ, 2008.

Os inquéritos são mencionados pela OMS como sendo uma forma de enviesar o estudo, devido ao facto de a maioria dos participantes serem as pessoas doentes. Outro problema muito referido na maioria dos estudos era o facto de não serem acautelados todos os factores, ou seja, todas as determinantes que influenciam ou podem influenciar o nosso estado de saúde (e.g., características socioeconómicas, comportamentos de risco e o percurso de vida).

O último grande estudo efectuado foi o de Draper et al., em 2005, e segundo J. Sá, em 2008, é tido por muitos cientistas como uma referência incontornável. Esta investigação abarcou a maior amostra populacional (Inglaterra, País de Gales e a Escócia), correspondendo a cerca de 59 milhões de pessoas, envolvendo as 29.081 crianças afectadas por cancro entre 1962 e 1995. É considerado um exemplo, pois não houve contacto com os investigados, já que foi utilizada uma metodologia de índole marcadamente geográfica, utilizando mapas digitalizados e os códigos postais como referência para identificar onde moravam os doentes. As conclusões deste estudo reconhecem uma relação/associação entre a proximidade das linhas e o aumento de incidência de leucemia infantil.

Em conclusão, podemos afirmar que apesar de já terem sido efectuados inúmeros estudos em torno da problemática dos campos electromagnéticos (emitidos pelas linhas de alta tensão), os resultados nunca foram conclusivos e segundo a OMS, na sua mais recente monografia de 2007, ainda é necessária mais investigação para tentar dissipar todas as dúvidas. Esta organização defende que todos os países devem promover e incentivar mais investigação e, acima de tudo, deviam (devem) promover activamente o princípio da precaução. Efeitos biológicos e patologias associadas aos campos
electromagnéticos

Muito tempo antes do primeiro estudo epidemiológico sobre os efeitos dos campos electromagnéticos e o aumento do risco de algumas patologias efectuado por Werthemeir e LeEPER em 1979, outros investigadores já estudavam as alterações provocadas pelos referidos campos no organismo humano, ao nível microscópico (e.g., células e átomos) e macroscópico.

Segundo P. DÉoux; S. DÉoux (1996) já em 1902, um abade de nome MoReux chamava a atenção para os possíveis efeitos das manchas solares e dos trovões magnéticos sobre a função psíquica dos homens, em especial no que concerne ao aumento de convulsões sociais e suicídios. Os mesmos autores ressaltaram a profunda subjectividade, variabilidade e a multicausalidade de algumas patologias (e.g., dores de cabeça, cansaço, mal-estar, excitabilidade, irritabilidade e insónias) que foram associadas a ambientes/lugares de elevada concentração de campos electromagnéticos de EBF.

No QUADRO II, podemos verificar as principais patologias associadasaos camposelectromagnéticos. Comoépossível observar, as patologias são de diversas índoles e segundo P. DÉoux; S. DÉoux (1996), começaram a ser sistematizadas sobretudo a partir da Segunda Guerra Mundial.

Contudo, e para evitar especulações e o pânico das populações, a OMS, desde 1996, estuda esta 
RISCOS - Associação Portuguesa de Riscos, Prevenção e Segurança

QUADro II - Efeitos biológicos associados à interacção entre campos electromagnéticos e o organismo humano.

\begin{tabular}{|c|l|}
\hline Tipologia & \multicolumn{1}{|c|}{ Patologias } \\
\hline Neurocomportamentos & Depressão, suicídio. \\
\hline Perturbações neurodegenerativas & Alzheimer, esclerose amiotrófica lateral (eléctrico), Parkinson. \\
\hline Imunologia e Hematologia & Aumento/diminuição de valores de referência (glóbulos vermelhos). \\
\hline Reprodução e desenvolvimento & Abortamento e malformação do feto. \\
\hline Cancro & $\begin{array}{l}\text { Leucemia infantil, linfomas, sistema nervoso central, cancro da mama feminino } \\
\text { e masculino. }\end{array}$ \\
\hline Outras patologias & Alterações no sistema endócrino (glândula pienal), alterações cardiovasculares. \\
\hline
\end{tabular}

Fonte: Elaboração própria com base em J. SÁ, 2008.

problemática, e, na sua monografia de 2007, intitulada Environmental Health Criteria 238: Extremely Low Frequency Fields, faz o ponto da situação sobre os conhecimentos comprovados até à data sobre os efeitos na saúde dos campos electromagnéticos de EBF.

A OMS (2007) afirma que não existe evidência adequada de correlação entre os campos electromagnéticos a EBF e as seguintes patologias: os neuro-comportamentos (e.g., depressão e suicídio); o sistema neuro-endócrino, mais concretamente a produção de melatonina e a sua relação com o cancro da mama; e as patologias neuro-degenerativas (e.g., Alzheimer, Parkinson e esclerose múltipla). Também não existe uma correlação clara entre os campos electromagnéticos e as alterações no sistema imunológico e hepático, bem como na reprodução e no desenvolvimento do feto. No que diz respeito às doenças cardiovasculares e ao cancro da mama, no mesmo estudo é afirmada a inexistência de qualquer correlação entre os campos electromagnéticos e as referidas patologias (J. Ś́, 2008).

Porém, e apesar de negar a maior parte dos efeitos biológicos presentes no QUADRo II, a OMS (2007) indica que a falta de conhecimento, a não percepção e identificação de mecanismos plausíveis não implicam a impossibilidade de efeitos na saúde dos indivíduos, mesmo com campos com níveis muito baixos.

Assim sendo, a OMS testou diversos mecanismos propostos para interacção directa entre os campos electromagnéticos a EBF e o corpo humano, sobressaindo três mecanismos: os campos eléctricos induzidos em redes neuronais, radicais livres e magnetite (J. SÁ, 2008; OMS, 2007). Dos três mecanismos, o que nos parece ser mais importante é o dos radicais livres. De realçar o facto de a elevada concentração de radicais livres estar associada ao desenvolvimento de inúmeras patologias (e.g., a diabetes, o envelhecimento celular, a aterosclerose, várias doenças neurológicas degenerativas), com especial destaque para o cancro (J. SÁ, 2008).

Os campos electromagnéticos parecem não ser inofensivos para a saúde. Contudo, e apesar de compreendermos as exigências por parte da OMS, que obriga a que os estudos sejam efectuados em mecanismos biofísicos, em animais e in vitro, ou até mesmo nos estudos epidemiológicos, pensamos que expressões como "predominantemente negativos", “inconclusivos", "resultados incompletos" ou "evidência considerada não adequada", utilizados nos seus documentos, em especial na sua monografia de 2007, devem ser considerados pertinentes e motivo de reflexão.

\section{Morbilidade oncológica na região Norte e no município de Guimarães}

Algumas características da freguesia de Serzedelo

Escolhemos Serzedelo, freguesia do município de Guimarães, como o nosso território objecto de estudo por vários motivos: em primeiro lugar, porque é uma freguesia que apresenta uma elevada densidade de postes e linhas de alta e muito alta tensão; em segundo lugar, é uma freguesia que, devido a pressões dos populares, já foi estudada ao nível da mortalidade pela Autoridade Regional de Saúde do Norte (ARSN), e, por último, por já ter sido alvo de cobertura mediática aquando da primeira manifestação, em 2008, do Movimento Nacional Contra a Alta Tensão em Zonas Habitadas (MNCATZH).

A freguesia de Serzedelo encontra-se atravessada por inúmeros postes e linhas de alta tensão, pois mesmo no limite entre a freguesia de Serzedelo (Guimarães) e a freguesia de Riba de Ave (Vila Nova de Famalicão), está sediada uma subestação. Esta subestação integra a rede nacional de transporte de energia eléctrica da Rede Eléctrica Nacional (REN), que está em funcionamento desde 1984, ainda que entre 1980 e 1984 tenham existido instalações provisórias (REN, 2008).

Segundo o relatório da REN de 2008, entre 1984 e 2007 a subestação foi constantemente melhorada, aumentando a sua capacidade de transformação e de transporte de energia eléctrica. Esse constante aumento de capacidade de transporte reflectiu-se no crescente povoamento dos territórios adjacentes aos postes e linhas de ala e muito alta tensão, sendo Serzedelo o melhor exemplo. 
$\mathrm{Na}$ figura 1, podemos observar a distribuição espacial da rede nacional de transporte de energia eléctrica da REN em Portugal Continental e no município de Guimarães. No município de Guimarães podemos realçar a expressiva encruzilhada de linhas que é possível observar no quadrante oeste do município, mais concretamente na fronteira entre o referido município e o de Vila Nova de Famalicão.
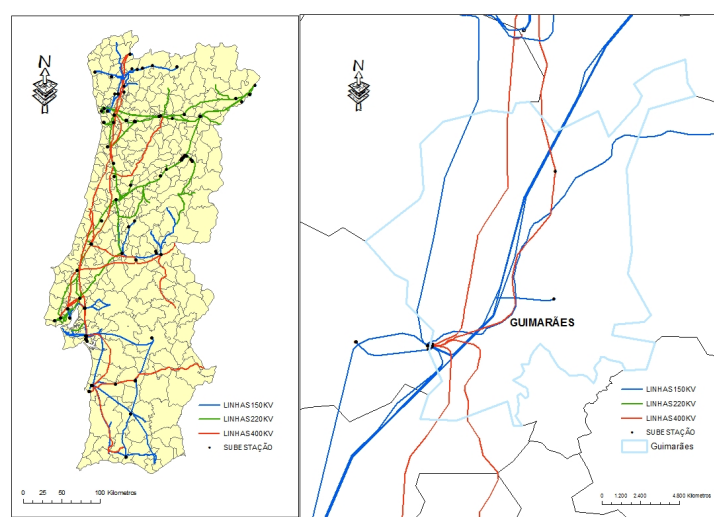

Fig. 1 - Mapa da rede nacional de transporte de energia eléctrica da R.E.N., em Portugal Continental e no município de Guimarães em 2009. (Fonte: Elaboração própria com dados da REN, 2009).

Segundo o relatório da REN (2008), existiam em 2008 diversas linhas com início ou com chegada à subestação de Riba de Ave. Mais concretamente, existem duas linhas de 400 Kilovolts (Kv) e sete de $150 \mathrm{Kv}$ e, ainda, quatro ramais que ligam algumas das linhas a subestações da rede de distribuição de energia eléctrica da Electricidade de Portugal (EDP).

Como consequência do crescente aumento da concentração de linhas e postes de alta e muito alta tensão na freguesia de Serzedelo, associado à crescente mediatização dos problemas associados aos campos electromagnéticos e motivada pela pressão exercida por habitantes locais e pela MNCATZA, a ARSN publicou, em 2008, um estudo intitulado "Risco de morrer em Guimarães - Análise da mortalidade entre 1997 e 2005".

Ao nível da metodologia, este trabalho caracterizase por realizar um estudo retrospectivo transversal com base nos certificados de óbito do Registo Civil de Guimarães entre 1 de Janeiro de 1995 e 31 de Dezembro de 2005.

As conclusões deste estudo adiantam que a taxa bruta de mortalidade apresentada é inferior à de Portugal Continental e à da região Norte, e que as principais causas de morte estão relacionadas com doenças do aparelho circulatório e as neoplasias malignas, com particular destaque para as neoplasias nos órgãos digestivos (ARSN, 2008).

Por fim, a principal conclusão deste estudo reside na não existência de diferenças significativas no risco de morrer e principais causas de morte na população residente no município de Guimarães, e nas respectivas freguesias (período entre 1997 e 2005), e quando comparado com o ocorrido na região Norte e em Portugal Continental (ARSN, 2008).

Contudo, este estudo merece-nos algumas críticas pois a fiabilidade da causa de morte pode ser posta em causa, facto para o qual os próprios autores do estudo alertam. Outro problema relevante é que os cancros que estão associados aos campos electromagnéticos são raros e bastante específicos, facto que este estudo ignorou, pois os óbitos por neoplasias malignas estavam agregados em grandes grupos (e.g., órgãos digestivos, respiratórios) quando deviam ter merecido uma maior desagregação. Para finalizar e na nossa opinião, o problema mais relevante deste estudo reside no facto do mesmo se ter centrado somente na mortalidade, ignorando a morbilidade por cancro, pois, e felizmente com os avanços na medicina, este tipo de doença passou a ser encarada como crónica e muitas pessoas que contraíram um cancro podem continuar a ser produtivas e virem a morrer de uma qualquer outra patologia.

\section{Breve descrição dos dados oncológicos da região Norte}

Devido à particularidade e raridade das doenças associadas aos efeitos dos campos electromagnéticos no organismo humano, a presente investigação foca-se na análise de dados sobre a morbilidade por cancro. Dentro dos cancros, a nossa atenção incide (mas não exclusivamente) nos cancros que costumam ser associados à problemática escolhida, como as leucemias, linfomas e tumores do sistema nervoso central (SNC).

Assim sendo, através do QUADRo III, conseguimos visualizar os registos oncológicos verificados na região Norte entre 2000 e 2005 , e podemos afirmar que no referido período de tempo, assiste-se, de ano para ano, a um aumento do número de casos de cancro. Este facto tem reflexo e é a inevitável consequência do envelhecimento da população e do consequente aumento da esperança de vida. Provavelmente, podemos ainda aditar que o aumento verificado resulta de uma maior preocupação com o registo destas patologias.

QUADRo III - Total de casos de cancro presentes nos Registos Oncológicos da Região Norte (RORENO) entre 2000 e 2005.

\begin{tabular}{|c|c|}
\hline Ano & Total \\
\hline 2000 & 9773 \\
\hline 2001 & 10060 \\
\hline 2002 & 10954 \\
\hline 2003 & 11813 \\
\hline 2004 & 12250 \\
\hline 2005 & 12950 \\
\hline
\end{tabular}

Fonte: Elaboração própria com base em dados fornecidos pelo RORENO Em 2010. 
Segundo o RoREno, em 2005, os tumores mais frequentes, logo com maior taxa de incidência, foram os do colo-rectal, da próstata, da mama e do estômago, o que já indica que os tumores associados a esta problemática (e.g., leucemias, linfomas e do SNC) não são muito frequentes.

No QUADRo IV podemos ver a evolução dos registos dos referidos tumores entre 2000 e 2005. Dos três tipos de cancro considerados, constatamos que os linfomas são os que apresentam um maior número de casos (3067), seguidos pelos tumores do SNC, e, por fim, temos as leucemias com 1085 registos. De referir ainda que no período considerado os tipos de cancros representados no QUADRO IV, apresentam um comportamento flutuante.

QUADRo IV - Tipos de cancro e respectivos registos na região Norte entre 2000 e 2005.

\begin{tabular}{|c|c|c|c|}
\hline \multirow{2}{*}{ Ano } & \multicolumn{3}{|c|}{ Tio de cancro } \\
\cline { 2 - 4 } & Leucemia & Linfoma & SNC \\
\hline 2000 & 205 & 406 & 169 \\
\hline 2001 & 170 & 488 & 167 \\
\hline 2002 & 151 & 395 & 181 \\
\hline 2003 & 209 & 555 & 207 \\
\hline 2004 & 180 & 562 & 200 \\
\hline 2005 & 170 & 607 & 212 \\
\hline Total & 1085 & 3067 & 1136 \\
\hline
\end{tabular}

Fonte: Elaboração própria com base em dados fornecidos pelo RORENO EM 2010

Análise dos registos do RORENo da freguesia de Serzedelo do município de Guimarães

Neste item vamos fazer um retrato mais específico dos registos verificados na freguesia de Serzedelo do município de Guimarães. A nossa atenção direccionase para os cancros mais frequentemente associados à influência/exposição de campos electromagnéticos. Esta análise só foi possível graças à resposta positiva por parte do Instituto Português de Oncologia do Porto a um pedido dirigido à sua direcção em inícios de 2010, no sentido de aceder a algumas variáveis que não estão publicadas para a escala de freguesia.

O QuAdro V, para além de conter os valores totais dos registos de tumores como, as leucemias, os linfomas e os do SNC, entre 2000 e 2005, também apresenta os registos dos referidos tumores no mesmo período de tempo no município de Guimarães.

As leucemias registadas em Guimarães entre 2000 e 2005 representam $4,3 \%$ das leucemias registadas na região Norte no mesmo período de tempo, enquanto os tumores do SNC registados no município de Guimarães registam a percentagem mais baixa $(3,7 \%)$.

O QUADRo V, é crucial para enfatizar o facto de estes tipos de tumores não serem muito frequentes, o que dificulta a tentativa de encontrarmos uma associação/relação entre elementos como os campos electromagnéticos produzidos pelas linhas e postes de alta e muito alta tensão e o aumento de incidência das referidas patologias/tumores.

QUADRo V - Tipos de cancro e respectivos registos na região Norte entre 2000 e 2005.

\begin{tabular}{|c|c|c|c|}
\hline $\begin{array}{c}\text { Tipo de } \\
\text { Cancro }\end{array}$ & $\begin{array}{c}\text { Região } \\
\text { Norte }\end{array}$ & Guimarães & $\begin{array}{c}\text { Percentagem } \\
\text { (\%) }\end{array}$ \\
\hline Leucemia & 1085 & 47 & 4,3 \\
\hline Linfoma & 3067 & 121 & 3,9 \\
\hline SNC & 1136 & 42 & 3,7 \\
\hline
\end{tabular}

Fonte: Elaboração própria com base em dados fornecidos pelo RORENO Em 2010

Através da leitura do QUADRo VI, podemos verificar que entre 2000 e 2006, foram efectuados 2947 registos de tumores. As freguesias que apresentam um maior número de registos estão também representadas no QUADRO VI, sendo de realçar que entre 2000 e 2006 foi a freguesia de Azurém que apresentou um maior número de registos, cerca de 188, o que representa cerca de $6,38 \%$ dos registos totais.

QUADRO VI - Registos oncológicos no município de Guimarães e respectivas freguesias entre 2000 e 2006.

\begin{tabular}{|c|c|c|}
\hline Freguesias & $\begin{array}{c}\text { Total de Registos } \\
\text { (2000-2006) }\end{array}$ & $\begin{array}{c}\text { Percentagem } \\
\text { (\%) }\end{array}$ \\
\hline Azurém & 188 & $6,38 \%$ \\
\hline $\begin{array}{c}\text { Guimarães } \\
\text { (São Paio) }\end{array}$ & 187 & $6,35 \%$ \\
\hline Creixomil & 184 & $6,24 \%$ \\
\hline Lordelo & 113 & $3,83 \%$ \\
\hline Selho (S. Jorge) & 113 & $3,83 \%$ \\
\hline Urgeses & 111 & $3,77 \%$ \\
\hline $\begin{array}{c}\text { Moreira de } \\
\text { Cónegos }\end{array}$ & 102 & $3,46 \%$ \\
\hline Ponte & 101 & $3,43 \%$ \\
\hline $\begin{array}{c}\text { Guimarães } \\
\text { (Oliveira do } \\
\text { Castelo) }\end{array}$ & 92 & $3,12 \%$ \\
\hline Fermentões & 76 & $2,58 \%$ \\
\hline Caldelas & 75 & $2,54 \%$ \\
\hline Serzedelo & 75 & $2,54 \%$ \\
\hline $\begin{array}{c}\text { Total do } \\
\text { município de } \\
\text { Guimarães }\end{array}$ & 2947 & $100 \%$ \\
\hline Fonte: Elaboraco & prom & \\
\hline
\end{tabular}

Fonte: Elaboração própria com base em dados fornecidos pelo RORENO Em 2010.

Das 69 freguesias que constituem o município de Guimarães, a nossa área de estudo, Serzedelo, é a décima segunda com maior número de registos, mais precisamente com 75 registos de tumores entre 2000 e 2006.

No QUADRo VII podemos ver a evolução dos registos verificados entre 2000 e 2006 em Serzedelo. De realçar que entre 2000 e 2006 se registaram oscilações no 
números de casos, sendo o ano de 2006 o que apresentou um maior número de casos, com 19 registos.

QUADRo VII - Registos oncológicos da freguesia de Serzedelo entre 2000 e 2006.

\begin{tabular}{|c|c|}
\hline Ano & Total \\
\hline 2000 & 11 \\
\hline 2001 & 4 \\
\hline 2002 & 12 \\
\hline 2003 & 12 \\
\hline 2004 & 8 \\
\hline 2005 & 9 \\
\hline 2006 & 19 \\
\hline Total & \\
\hline
\end{tabular}

Fonte: Elaboração própria com base em dados fornecidos pelo RoRENo em 2010.

O QUADRO VIII pormenoriza a localização dos tumores verificados em Serzedelo entre 2000 e 2006. Depois de analisar as publicações do RORENO entre 1999 e 2005, verificamos que ao longo do referido período de tempo os cancros com maior expressão na Região Norte são, o colorectal, o do estômago, o do pulmão, o da próstata e o da mama. Seguindo a mesma linha de pensamento, verificamos no QUADRo VIII, que a freguesia de Serzedelo apresenta um comportamento semelhante ao da região Norte.

QUADRo VIII - Registos oncológicos em Serzedelo por diferentes tipos de localização entre 2000 e 2006.

\begin{tabular}{|c|c|c|}
\hline Localização do tumor & Número de casos & Percentagem (\%) \\
\hline Aparelho Digestivo (outros) & 3 & $4,0 \%$ \\
\hline Aparelho Genital (outros) & 1 & $1,3 \%$ \\
\hline Bexiga & 4 & $5,3 \%$ \\
\hline Cabeça e Pescoço & 5 & $6,7 \%$ \\
\hline Cólon & 4 & $5,3 \%$ \\
\hline Esófago & 2 & $2,7 \%$ \\
\hline Estômago & 16 & $21,3 \%$ \\
\hline Laringe & 3 & $4,0 \%$ \\
\hline Linfomas & 5 & $6,7 \%$ \\
\hline Mama & 11 & $14,7 \%$ \\
\hline Melanoma da Pele & 1 & $1,3 \%$ \\
\hline Próstata & 3 & $4,0 \%$ \\
\hline Pulmão & 8 & $10,7 \%$ \\
\hline Recto & 3 & $4,0 \%$ \\
\hline $\operatorname{Rim}$ & 1 & $1.3 \%$ \\
\hline Tiróide & 3 & $4.0 \%$ \\
\hline Útero & 1 & $1,3 \%$ \\
\hline Cérebro & 0 & $0 \%$ \\
\hline Cólon do Útero & 0 & $0 \%$ \\
\hline Leucemia & 0 & $0 \%$ \\
\hline $\begin{array}{l}\text { Primário de Origem } \\
\text { Desconhecida }\end{array}$ & 0 & $0 \%$ \\
\hline Outros & 1 & $1,3 \%$ \\
\hline Total & 75 & $100 \%$ \\
\hline
\end{tabular}

Fonte: Elaboração própria com base em dados fornecidos pelo RORENO Em 2010.
O QUADRo IX é deveras importante pois nele estão presentes os cancros que são frequentemente associados aos campos electromagnéticos. Como podemos verificar, em Serzedelo, entre 1996 e 2006, foram registados 5 linfomas, enquanto que não se verificaram registos de leucemias e de cancros do sistema nervoso central.

Podemos então inferir que Serzedelo até ao ano de 2006 não confirma a tendência dos estudos epidemiológicos internacionais, pois "apenas" foram diagnosticados 5 linfomas, mas devemos sobretudo destacar que não foi diagnosticada nenhuma leucemia, doença que era a mais destacada e mais ressaltada nos estudos epidemiológicos internacionais.

QuAdRo IX - Registos oncológicos da freguesia de Serzedelo entre 1996 e 2006.

\begin{tabular}{|c|c|c|c|}
\hline & Leucemias & Linfomas & S.N.C. \\
\hline $1996-2006$ & 0 & 5 & 0 \\
\hline
\end{tabular}

Fonte: Elaboração própria com base em dados fornecidos pelo RORENO em 2010.

Metodologia proposta para a avaliação do risco da população de Serzedelo (Guimarães)

\section{Características da metodologia utilizada}

Tratando-se de uma problemática pouco estudada até ao momento em Portugal, que encerra um elevado grau de complexidade, e como pretendemos explorar uma suposta relação de associação e ou de causalidade, optámos por efectuar um estudo do tipo "expostos e não expostos".

Isto foi possível porque pretendemos avaliar os efeitos de um elemento, os campos electromagnéticos emitidos pelas linhas de alta e muito alta tensão, na saúde da população de Serzedelo, e sabendo que a partir de uma fonte de emissão dos referidos campos a energia ou intensidade dos campos diminui em função do quadrado da distância da fonte (P. DÉoux; S. DÉoux, 1996).

Este tipo de estudo visa seleccionar dois grupos populacionais diferentes: um grupo exposto aos campos electromagnéticos emitidos pelas linhas de alta e muito alta tensão; e outro grupo da mesma freguesia (Serzedelo) que não esteja exposto aos campos electromagnéticos emitidos pelas linhas acima referidas.

Para definir os grupos populacionais, foi utilizada cartografia do município de Guimarães, mais concretamente da freguesia de Serzedelo. Recorrendo ao ArcMap, mais concretamente à cartografia do edificado e das linhas de alta tensão de Serzedelo, foi efectuada uma Selecção por Localização (Select by Location) de todas as habitações que se encontram até 50 metros das referidas linhas, estando assim definido o grupo dos expostos do nosso estudo (fig. 2). 
146

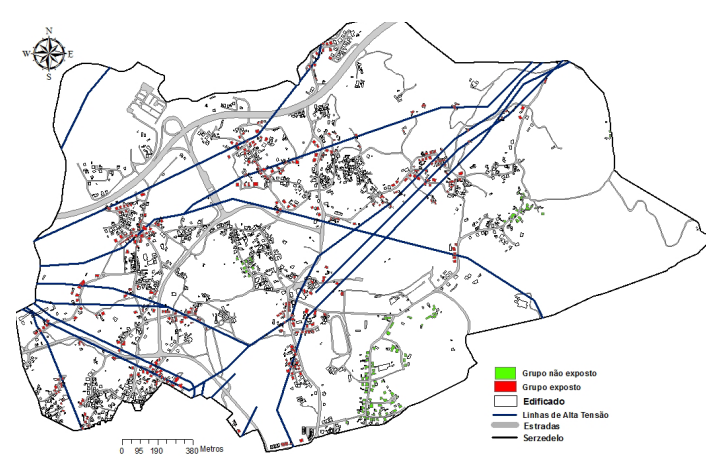

Fig. 2 - Habitações expostas e não expostas aos campos electromagnéticos das linhas de alta tensão na freguesia de Serzedelo.

(Fonte: Elaboração própria através da Cartografia Digital fornecida em Abril de 2010 pela

Câmara Municipal de Guimarães)

Para delimitarmos o grupo dos não expostos, efectuámos a mesma operação, divergindo apenas a distância, ou seja, realizámos uma Selecção por Localização de todas as habitações que se encontram a uma distância igual ou superior a 250 metros das linhas de alta tensão, pois os campos electromagnéticos perdem intensidade conforme nos vamos afastando da fonte dos mesmos, sendo mais intensos nos primeiros 50 metros. Alguns estudos epidemiológicos internacionais definem que, a partir dos 200 metros, o risco para a saúde da população são raros ou nulos.

Como estamos a estudar esta problemática à escala local (freguesia) e por não dispormos de dados de morbilidade e de mortalidade muito desagregados em termos de patologias, considerámos essencial a realização de um inquérito por entrevista semi-estruturada, que tenta aferir os efeitos dos campos electromagnéticos "emitidos" pelas linhas de alta e muito alta tensão e de alguns electrodomésticos (e.g., micro-ondas, frigorífico, máquina de barbear, secador de cabelo) na saúde da população de Serzedelo.

No nosso ponto de vista, o inquérito por entrevista semiestruturada é essencial para tentar perceber o estado de saúde dos dois grupos populacionais definidos. A realização do inquérito permite a observação, a pormenorização e a compreensão dos sintomas e das patologias que afectam e/ou afectaram os indivíduos inquiridos.

O objectivo principal da realização do inquérito reside na tentativa de percepcionar se existem sintomas ou patologias não coincidentes no grupo dos expostos e dos não expostos que nos permita afirmar se a proximidade às linhas de alta e muito alta tensão pode, ou não, influenciar o estado de saúde e ou potenciar o surgimento de determinados sintomas ou patologias. Considerámos os que têm sido mais utilizados nos trabalhos realizados à escala internacional, nomeadamente, os vários tipos de cancro, as doenças do sangue, o Parkinson, o Alzheimer, o abortamento, o distúrbio do sono (insónias), a esclerose múltipla, as cefaleias, a depressão e a irritabilidade.

O guião de entrevista está dividido em quatro grandes grupos temáticos, pretendendo traçar o perfil geográfico e socioeconómico dos inquiridos, bem como precisar os anos e o tempo de exposição diária aos campos electromagnéticos das linhas de alta e muito alta tensão, assim como a vários electrodomésticos, não olvidando também a utilização do telemóvel. Pretendemos também averiguar e conhecer um pouco do percurso de vida dos inquiridos com especial atenção para alguns comportamentos e estilos de vida (e.g., se fuma, se pratica exercício). No QUADRo X podemos observar os grupos temáticos contemplados no guião de entrevista, que prevê 26 questões e foi aplicado a 118 indivíduos expostos e a 55 indivíduos não expostos no período que mediou entre Julho e Dezembro de 2010. O presente inquérito deve ser encarado como um estudo piloto que permita, num futuro próximo, em colaboração com outras instituições (e.g., Instituto Português de Oncologia), proceder a um estudo mais completo.

Quadro X - Grupos temáticos usados no guião de entrevista.

\section{Grupos temáticos}

1-Caracterização geográfica e socioeconómica (sexo, idade, nível de instrução, profissão, anos de residência em Serzedelo).

2-Hábitos quotidianos e no decurso da vida (e.g., como passa o dia, realização de actividade física, consumo de tabaco).

3-Questões sobre a habitação (e.g., horas de permanência diária em casa, parte da habitação onde permanece mais tempo, electrodomésticos que possui, local da habitação onde se encontram, frequência de utilização dos mesmos, presença de electrodomésticos no quarto de dormir, uso do telemóvel).

4-Passado e presente em termos de patologias (e.g., motivos que levam o inquirido a consultar o médico de família, se sofre ou sofreu de algum tipo de doença, caso sofra ou tenha sofrido, quando foi diagnosticada e que idade tinha, algum familiar ou amigo/conhecido padecem do mesmo problema, como considera o inquirido o seu estado de saúde actual, informação do inquirido relativamente à influência dos cabos e postes de alta tensão e de alguns electrodomésticos na saúde das pessoas).

Fonte: Guião de entrevista usado no inquérito em curso desde Julho de 2010.

Os requisitos considerados importantes para um determinado indivíduo fazer parte da amostra foram:

- residir na freguesia de Serzedelo, mais concretamente naquele lugar (área exposta ou não exposta) há, pelo menos, dez anos;

- ter 40 ou mais anos de idade, porque a probabilidade de se contrair um cancro 
aumenta proporcionalmente com o avançar da idade. Por outro lado, o cancro não é uma doença que se desenvolve, em grande parte dos casos, num período curto, ou seja, os indivíduos que têm cancro na actualidade reflectem aproximadamente os comportamentos e as vivências de há, pelo menos, uma década atrás. Contudo, aceitámos inquirir 1 indivíduo de 14 anos, porque este revelou capacidade para responder às questões colocadas e para representar o agregado familiar. Nas inúmeras saídas de campo realizadas nunca foi possível falar com os pais deste jovem.

0 guião de entrevista permite aferir também a existência de vários sintomas/patologias (e.g., cancro, diabetes, hipertensão, dores de cabeça crónicas, irritabilidade, abortamento, insónias) nos familiares, incluindo os mais jovens.

Análise dos grupos populacionais em estudo - resultados preliminares

Como foi referido anteriormente, foi realizado um inquérito por entrevista a dois grupos populacionais, o dos expostos e dos não expostos. O QUADRo XI apresenta algumas características demográficas (sexo e idade) da população inquirida.

No grupo dos expostos foram inquiridas 118 pessoas, enquanto no grupo dos não expostos o número de inquiridos foi somente de 55. A diferença no número de inquiridos em função da exposição pode ser explicada por serem em menor número as áreas de residência dos indivíduos não expostos (360 residências "expostas" e apenas 98 “não expostas" (ver figura 2).

Dos 118 inquiridos no grupo dos expostos, 59 são do sexo feminino (50\%). No grupo dos 55 inquiridos não expostos, 18 pertencem ao sexo masculino e 37 ao sexo feminino $(67,3 \%)$. A diferença na composição dos grupos em função do género é relevante e terá, necessariamente, que ser considerada nas análises que forem posteriormente efectuadas, uma vez que os resultados em saúde são fortemente condicionados por este factor. Vários autores têm vindo a reportar diferenças de género na auto-avaliação do estado de saúde, na morbilidade, no reconhecimento dos sintomas da doença, na procura de cuidados de saúde, nos comportamentos de actividade física e tabágicos, aspectos que estão contemplados nas entrevistas efectuadas. Como exemplo, refira-se que as mulheres reportam tendencialmente piores estados de saúde (Nogueira, 2008); assim, no grupo dos expostos, o estado de saúde pode ser melhor do que o esperado, melhor até do que o reportado pelo grupo dos não expostos, unicamente pelo facto deste grupo possuir menor percentagem de mulheres do que o grupo dos não expostos.
No que concerne à idade dos inquiridos, podemos referir do total da amostra ( $n=173), 69,4 \%$ (120 indivíduos) apresenta uma idade igual ou superior a 50 anos. A idade média dos inquiridos é semelhante nos dois grupos de inquiridos: 54,7 e 53,1 anos, respectivamente, para o grupo dos não expostos e dos expostos. 0 desvio-padrão varia um pouco mais entre os dois grupos $(14,7$ e 11,5 anos, respectivamente, para não expostos e expostos), sublinhando uma maior variação na idade dos indivíduos pertencentes ao grupo dos não expostos; o coeficiente de variação é de $21,1 \%$ no grupo dos expostos e de $27,8 \%$ no dos não expostos.

Analisando o QUADRo XI, verificamos que no grupo dos expostos o maior número dos inquiridos ( 48 dos 118 , ou seja, $40,7 \%$ ) apresenta idades entre os 50 e os 59 anos. Seguidamente, temos o grupo etário dos 40 aos 49 anos, com 29 dos 118 inquiridos (24,6\%). O grupo etário que tem menor expressão é o dos 14 aos 39 anos $(5,1 \%)$.

No grupo dos não expostos, é também o escalão etário dos 50 aos 59 anos que apresenta maior frequência, mas num valor relativo consideravelmente inferior $(27,3 \%$, para $40,7 \%$ no grupo dos expostos). Segue-se o grupo etário dos 60 aos 69 anos, com 14 dos 55 inquiridos (25,4\%). O primeiro grupo etário considerado, 14 a 39 anos, apresenta $20 \%$ do número total de inquiridos deste grupo, enquanto para o grupo dos expostos esta percentagem ficava pelos 5,1\%. Sabendo que a idade é um dos factores que mais condiciona a saúde, a variação que constatámos na idade dos indivíduos inquiridos, alerta-nos para a necessidade de considerarmos a idade em todas as análises a que os dados forem posteriormente submetidos. Populações jovens e envelhecidas apresentam perfis epidemiológicos bastante diferentes, pois enquanto os jovens revelam uma maior morbilidade e mortalidade por doenças infecciosas, os mais idosos apresentam uma maior propensão para contrair doenças crónicas e degenerativas.

Relacionando o sexo com a idade, podemos ainda mencionar que, no grupo dos expostos, $44,1 \%$ dos inquiridos do sexo feminino (26 dos 59) têm idades entre os 50 e os 59 anos, seguindo-se o grupo etário dos 40 aos 49 anos, com 27,1\% (16 dos 59 inquiridos). Também no grupo dos expostos, no que concerne ao sexo masculino, verificamos que grupo grupo etário mais representativo é os dos 50 aos 59 anos, com $37,3 \%$ dos inquiridos (22 do total de 59 ), logo seguido pelo grupo etário dos 60 aos 69 anos, com $27,1 \%$ dos inquiridos (16 dos 59).

No grupo dos não expostos, observamos que $24,3 \%$ inquiridos do sexo feminino têm idades compreendidas entre os 50 e os 59 anos, valor semelhante ao apresentado pelo grupo etário dos 14 aos 39 anos. Segue-se, com $21,6 \%$, o grupo etário dos 60 aos 69 anos. Concluímos 
que os indivíduos inquiridos do sexo feminino no grupo dos não expostos são tendencialmente mais jovens, por comparação com os dos restantes grupos (não expostos do sexo masculino; expostos de ambos os sexos).

Esta análise da amostra permite-nos afirmar que o sexo e a idade, duas das variáveis imutáveis que podem explicar variações em saúde, conjugam-se na nossa amostra de forma a poderem explicar algumas diferenças na saúde dos grupos em estudo, o que sublinha a necessidade de considerar estas determinantes em análises posteriores. Isto significa, concretamente, que os modelos de regressão logística que pensamos desenvolver terão que ser ajustados, pelo menos, para sexo e idade. feminino, possui o primeiro ciclo do ensino básico (64,4\% para ambos os sexos). Neste grupo, 7,6\% dos inquiridos possui o Ensino Secundário e 1,7\%, o Ensino Médio ou Superior. Apesar de algumas semelhanças entre os géneros ao nível da escolaridade, verificamos que existem diferenças importantes, realçando-se sobretudo o facto de $3,4 \%$ dos inquiridos do sexo feminino não saberem ler nem escrever (dois indivíduos) e de 3,4\% dois inquiridos do sexo masculino (dois inquiridos) possuírem curso superior.

Centrando a análise no grupo dos 55 inquiridos não expostos, verificamos que 47,3\% (26 indivíduos) tem o primeiro Ciclo do Ensino Básico, 21,8\% (12 indivíduos)

QUADRo XI - Caracterização por sexo e grupo etário dos grupos inquiridos

\begin{tabular}{|c|c|c|c|c|c|c|c|}
\hline \multirow{3}{*}{ Grupos } & \multirow{3}{*}{ Grupos etários } & \multicolumn{4}{|c|}{ Sexo } & \multirow{2}{*}{\multicolumn{2}{|c|}{ Total }} \\
\hline & & \multicolumn{2}{|c|}{ Masculino } & \multicolumn{2}{|c|}{ Feminino } & & \\
\hline & & Número & Percentagem & Número & Percentagem & Número & Percentagem \\
\hline \multirow{5}{*}{ 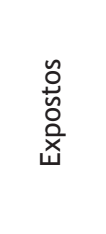 } & De 14 a 39 anos & 4 & 6,8 & 2 & 3,4 & 6 & 5,1 \\
\hline & De 40 a 49 anos & 13 & 22,0 & 16 & 27,1 & 29 & 24,5 \\
\hline & De 50 a 59 anos & 22 & 37,3 & 26 & 44,1 & 48 & 40,7 \\
\hline & De 60 a 69 anos & 16 & 27,1 & 9 & 15,2 & 25 & 21,2 \\
\hline & De 71 a 83 anos & 4 & 6,8 & 6 & 10,2 & 10 & 8,5 \\
\hline Total & & 59 & 100 & 59 & 100 & 118 & 100 \\
\hline \multirow{5}{*}{ 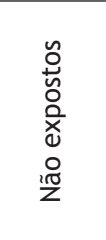 } & De 14 a 39 anos & 2 & 11,1 & 9 & 24,3 & 11 & 20,0 \\
\hline & De 40 a 49 anos & 1 & 5,5 & 6 & 16,2 & 7 & 12,7 \\
\hline & De 50 a 59 anos & 6 & 33,3 & 9 & 24,3 & 15 & 27,3 \\
\hline & De 60 a 69 anos & 6 & 33,3 & 8 & 21,6 & 14 & 25,4 \\
\hline & De 71 a 83 anos & 5 & 27,8 & 5 & 13,5 & 8 & 14,6 \\
\hline Total & & 18 & & 37 & 100 & 55 & 100 \\
\hline
\end{tabular}

Fonte: Inquérito realizado à população da freguesia de Serzedelo entre Julho e Dezembro de 2010.

No QuAdro XII, temos representado o nível de escolaridade por sexo dos indivíduos inquiridos. 0 nível de escolaridade, um dos indicadores do estatuto socioeconómico, é também um factor determinante dos resultados em saúde. Indivíduos de maior escolaridade possuem, geralmente, melhores níveis de saúde, o que se explica por um conjunto de factores relacionados com o estatuto socioeconómico, como a capacidade de comprar bens e serviços, o acesso à informação e os comportamentos. É, por isso, um dos factores que deve ser tido em conta nas análises estatísticas que procuram explicar os resultados em saúde.

No grupo dos expostos, a maioria dos indivíduos - 64,4\% (76 dos 118) - possui apenas o primeiro ciclo do ensino básico. Segue-se o terceiro ciclo do ensino básico $\left(9^{\circ}\right.$ ano ou antigo $5^{\circ}$ ano do liceu), com $13,6 \%$ dos inquiridos. Analisando agora o nível de escolaridade segundo o sexo dos indivíduos expostos, constatamos que a maioria dos inquiridos, quer do sexo masculino, quer do sexo possui o segundo Ciclo do Ensino Básico (antigo ensino Preparatório), 12,7\% tem o Ensino Secundário e 3,6\%, o Médio ou Superior. No entanto, neste grupo, 7,3\% dos inquiridos (4 indivíduos) não sabem ler nem escrever. Comparativamente ao grupo dos inquiridos expostos, conclui-se pela maior heterogeneidade no grupo dos não expostos que apresenta, simultaneamente, maior percentagem de indivíduos com os níveis máximos e mínimos de escolaridade.

Dos 37 inquiridos não expostos do sexo feminino, 48,6\% apresentam o primeiro ciclo do ensino básico, 21,6\% o segundo Ciclo do Ensino Básico (antigo ensino Preparatório), 8,1\% são analfabetos e 5,4\% possui curso Médio ou Superior. Verificamos, assim, que para a heterogeneidade acima referida, contribuem sobretudo os inquiridos do sexo feminino, uma vez que são estes que revelam, em simultâneo, percentagens maiores de indivíduos analfabetos e de indivíduos com o ensino médio ou superior. 
A análise da escolaridade nos dois grupos de inquiridos destaca uma diferença importante entre eles: no grupo dos expostos, 70,3\% dos inquiridos possui, como nível máximo de escolaridade, o primeiro ciclo do Ensino Básico (estes inquiridos possuem a antiga quarta classe ou menos), e apenas $9,3 \%$ possui um nível de ensino superior ao ensino básico obrigatório (secundário e médio ou superior). No grupo dos não expostos, a percentagem de inquiridos com a quarta classe ou menos é de $56,4 \%$, enquanto a percentagem de inquiridos com nível de escolaridade mais elevado (secundário e médio ou superior) é de 16,3\%. Esta diferença, para além de poder condicionar diferenças na saúde, deve ser posteriormente abordada de uma perspectiva de "justiça ambiental", ou “amplificação da privação” (MACINTYRE, 2007; NoguelRA, 2010). A questão que devemos colocar é a da ocorrência, em Serzedelo, de um modelo de amplificação de riscos em saúde, caracterizado por uma acumulação de desvantagens individuais e ambientais. Concretizando, é possível que indivíduos mais vulneráveis, pelo seu estatuto socioeconómico, neste caso, pela sua menor escolaridade, vejam a sua vulnerabilidade ser potenciada pelo local em que residem, uma vez que se tratam de áreas de maior exposição aos riscos electromagnéticos. Esta é uma hipótese que merece ser investigada e à qual nos dedicaremos no futuro.

QUADRo XII - Nível de escolaridade por sexo dos indivíduos inquiridos do grupo dos expostos e dos não expostos

\begin{tabular}{|c|c|c|c|c|c|c|c|}
\hline \multirow[t]{3}{*}{ Grupos } & \multirow{3}{*}{ Nível de escolaridade } & \multicolumn{4}{|c|}{ Sexo } & \multirow{2}{*}{\multicolumn{2}{|c|}{ Total }} \\
\hline & & \multicolumn{2}{|c|}{ Masculino } & \multicolumn{2}{|c|}{ Feminino } & & \\
\hline & & Número & Percentagem & Número & Percentagem & Número & Percentagem \\
\hline \multirow{7}{*}{ 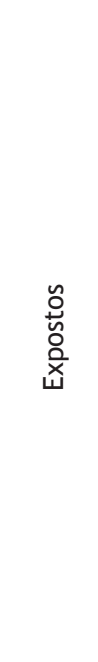 } & Não sabe ler nem escrever & 0 & 0,0 & 2 & 3,4 & 2 & 1,7 \\
\hline & $\begin{array}{l}\text { Sabe ler e escrever sem ter } \\
\text { frequentado o sistema de } \\
\text { ensino }\end{array}$ & 4 & 6,8 & 1 & 1,7 & 5 & 4,2 \\
\hline & $\begin{array}{lll}\text { Primeiro } & \text { Ciclo do } & \text { Ensino } \\
\text { Básico } & \text { (antiga } & \text { quarta } \\
\text { classe) } & & \\
\end{array}$ & 38 & 64,4 & 38 & 64,4 & 76 & 64,4 \\
\hline & $\begin{array}{lll}\text { Segundo Ciclo do } & \text { Ensino } \\
\text { Básico (antigo } & \text { ensino } \\
\text { Preparatório). } & \end{array}$ & 5 & 8,5 & 3 & 5,1 & 8 & 6,8 \\
\hline & $\begin{array}{l}\text { Terceiro Ciclo do Ensino } \\
\text { Básico ( } 9^{\circ} \text { ano ou antigo } 5^{\circ} \\
\text { ano do liceu) }\end{array}$ & 6 & 10,2 & 10 & 16,9 & 16 & 13,6 \\
\hline & Ensino Secundário & 4 & 6,8 & 5 & 8,5 & 9 & 7,6 \\
\hline & Curso Médio ou Superior & 2 & 3,4 & 0 & 0,0 & 2 & 1,7 \\
\hline \multirow{8}{*}{ 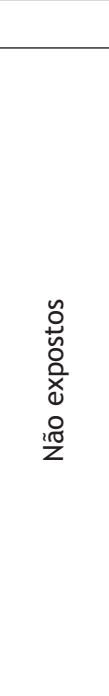 } & Total & 59 & 100 & 59 & 100 & 118 & 100 \\
\hline & \multirow{2}{*}{$\begin{array}{l}\text { Não sabe ler nem escrever } \\
\text { Sabe ler e escrever sem ter } \\
\text { frequentado o sistema de } \\
\text { ensino }\end{array}$} & 1 & 5,6 & 3 & 8,1 & 4 & 7,3 \\
\hline & & 0 & 0,0 & 1 & 2,7 & 1 & 1,8 \\
\hline & $\begin{array}{lll}\text { Primeiro } & \text { Ciclo do } & \text { Ensino } \\
\text { Básico } & \text { (antiga } & \text { quarta } \\
\text { classe). } & & \\
& & \end{array}$ & 8 & 44,4 & 18 & 48,6 & 26 & 47,3 \\
\hline & $\begin{array}{lll}\begin{array}{l}\text { Segundo Ciclo do } \\
\text { Básico (antigo }\end{array} & \text { ensino } \\
\text { Preparatório). } & \\
\end{array}$ & 5 & 27,8 & 8 & 21,6 & 12 & 21,8 \\
\hline & $\begin{array}{l}\text { Terceiro Ciclo do Ensino } \\
\text { Básico ( } 9^{\circ} \text { ano ou antigo } 5^{\circ} \\
\text { ano do liceu) }\end{array}$ & 1 & 5,6 & 2 & 5,4 & 3 & 5,5 \\
\hline & Ensino Secundário & 3 & 16,6 & 4 & 10,8 & 7 & 12,7 \\
\hline & Curso Médio ou Superior & 0 & 0,0 & 2 & 5,4 & 2 & 3,6 \\
\hline & Total & 18 & 100 & 37 & 100 & 55 & 100 \\
\hline
\end{tabular}

Fonte: Inquérito realizado à população da freguesia de Serzedelo entre Julho e Outubro de 2010. 
No QUADRO XIII examinamos uma das mais importantes características dos dois grupos inquiridos, a exposição a Serzedelo, mais concretamente há quanto tempo (em anos) os inquiridos habitam em Serzedelo. Esta variável é muito importante, pois a exposição frequente e prolongada ao longo do tempo (décadas) a um factor ou agente de risco é um aspecto importante na etiologia de um cancro.

Em relação ao total da amostra, verifica-se uma média de anos de residência em Serzedelo de 39,5 anos; este valor é de 41,4 anos no grupo dos expostos e de 35,3 anos no grupo dos não expostos. Além da diferença apresentada pelos valores das médias, verifica-se que diferem também os valores dos desvios-padrão, concluindo-se pela maior variabilidade dos anos de residência em Serzedelo no grupo dos não expostos; o desvio-padrão é de 19,5 anos e de 17,2 anos, respectivamente, para o grupo dos não expostos e expostos e o coeficiente de variação, sempre elevado, é de $55,3 \%$ no grupo dos inquiridos não expostos e de $41,5 \%$ no grupo dos inquiridos expostos.

Analisando o QUADRo XIII, verificamos que no grupo dos expostos, $39,8 \%$ dos inquiridos (47 dos 118 ) apresentam já um longo período de permanência em Serzedelo (40 a 59 anos). Temos também 31,4\% de inquiridos (37) que habitam em Serzedelo há mais de 21 anos, mas menos de 39 anos, seguindo-se, em termos percentuais, os inquiridos que revelam um período de exposição de 60 e mais anos (15,3\%). Apenas 13,5\% dos inquiridos reside em Serzedelo há menos de 20 anos. Analisando o tempo de residência em função do sexo, verificamos que as mulheres apresentam, tendencialmente, maior variabilidade: é neste sexo que surgem, em simultâneo, os menores tempos de residência $(15,3 \%$ das mulheres residem em Serzedelo há menos de 20 anos, contra um valor de $11,9 \%$ no sexo masculino) e os maiores (16,9\% das mulheres com 60 e mais anos de residência no local, contra um valor de $13,5 \%$ nos homens).

Dos 55 inquiridos do grupo dos não expostos, 38,2\% (21) dos inquiridos apresentam um período de residência em Serzedelo de 21 a 39 anos, seguindo-se, por ordem decrescente de importância, os que residem num período compreendido entre os 40 e os 59 anos $(21,8 \%)$ e 60 e mais anos $(16,4 \%)$. De realçar ainda que $23,6 \%$ dos inquiridos do grupo dos não expostos (13 dos 55), apresentam um período de residência máximo de 20 anos, concluindo-se que neste grupo o tempo de residência em Serzedelo é consideravelmente menor, como aliás tinha sido já revelado pelo valor do tempo médio.

Estes resultados estão coadunantes com o facto das áreas não expostas às linhas e postes de alta e muito alta tensão serem de urbanização mais recente do que áreas de residência dos inquiridos expostos. Acresce a possibilidade de ocorrência de um mecanismo de mobilidade selectiva, condicionado pelo estatuto socioeconómico, que agrava a questão da justiça ambiental atrás referida. Indivíduos expostos, de menor estatuto socioeconómico, podem ter mais dificuldades em mudar de área de residência, dados os seus constrangimentos económicos, aumentando assim o tempo de residência em Serzedelo.

O QUADRo XIV expõe o número de anos na actual residência à data do inquérito. A amostra inquirida apresenta, em média, um período de residência na casa actual de 26,6 anos, valor que é de 26,97 anos para o grupo dos expostos versus 25,9 anos para o grupo dos não expostos. Além do grupo dos expostos apresentar, em termos médios, um maior número de anos de permanência na residência, é também neste grupo que se verifica uma menor heterogeneidade em relação a esta característica (desvio-padrão de 16,2 anos e coeficiente de variação de $60 \%$, para um desvio-padrão de 18,4 anos e coeficiente de variação superior a $70 \%$ no grupo dos não expostos).

Dos 118 inquiridos do grupo dos expostos, 33,1\% (39 indivíduos) habitam na actual residência há um período que varia entre os 10 e os 20 anos, seguindo-se $25,4 \%$ de inquiridos (30) com 21 a 30 anos de permanência na actual habitação. De referir ainda que apenas 19,5\% dos inquiridos (23) do grupo dos expostos apresenta um período de permanência na casa actual igual ou superior a 41 anos. Temos, por outro lado, apenas 10,1\% de inquiridos (12 dos 118) que apresentam períodos de residência na habitação actual inferiores a 10 anos.

No grupo dos não expostos, 25,5\% dos inquiridos (14 dos 55) apresenta um período de residência na casa actual entre 21 a 30 anos. De destacar que 18,2\% (10 dos 55 inquiridos) apresentam um período máximo de residência na casa actual inferior a 10 anos, valor consideravelmente superior ao verificado no grupo dos expostos $(10,1 \%)$. Todavia, em relação à percentagem de inquiridos cujo período de permanência na casa actual é igual ou superior a 41 anos, verificamos alguma semelhança entre os dois grupos $(18,2 \%$ nos grupo dos não expostos e $19,5 \%$ no dos expostos).

O QUADRO XV apresenta a auto-avaliação do estado de saúde da população inquirida. Ainda que este não fosse um objectivo inicial deste trabalho, optámos por fazer uma breve avaliação ao estado de saúde da população, não tanto para verificar o estado desse estado de saúde, mas principalmente para verificarmos se existem, ou não, variações entre os grupos em estudo. Por esse motivo, utilizou-se a questão relativa à auto-avaliação do estado de saúde, e não as perguntas da entrevista cuja informação relativa à saúde é mais detalhada (por exemplo, morbilidades sentidas). Refira-se, no entanto, que este indicador subjectivo apresenta fortes correlações com as determinantes da saúde, biológicas, sociais e comportamentais, nomeadamente com o género e a idade, a ocupação e a escolaridade, o consumo 
territorium 19

Quadro XIII - Período de residência em Serzedelo por sexo no grupo dos expostos e não expostos.

\begin{tabular}{|c|c|c|c|c|c|c|}
\hline \multicolumn{7}{|c|}{ Grupo dos Expostos } \\
\hline & Masculino & Percentagem & Feminino & Percentagem & Total & Percentagem \\
\hline$<10$ anos & 1 & 1,7 & 2 & 3,4 & 3 & 2,5 \\
\hline De 10 a 20anos & 6 & 10,2 & 7 & 11,9 & 13 & 11,0 \\
\hline De 21 a 39 anos & 23 & 39,0 & 14 & 23,7 & 37 & 31,4 \\
\hline De 40 a 59 anos & 21 & 35,6 & 26 & 44,1 & 47 & 39,8 \\
\hline 60 e mais anos & 8 & 13,5 & 10 & 16,9 & 18 & 15,3 \\
\hline Total & 59 & 100 & 59 & 100 & 118 & 100 \\
\hline \multicolumn{7}{|c|}{ Grupo dos não Expostos } \\
\hline$<10$ anos & 2 & 11,1 & 4 & 10,8 & 6 & 10,9 \\
\hline De 10 a 20anos & 2 & 11,1 & 5 & 13,5 & 7 & 12,7 \\
\hline De 21 a 39 anos & 7 & 38,9 & 14 & 37,8 & 21 & 38,2 \\
\hline De 40 a 59 anos & 4 & 22,2 & 8 & 21,6 & 12 & 21,8 \\
\hline 60 e mais anos & 3 & 16,7 & 6 & 16,2 & 9 & 16,4 \\
\hline Total & 18 & 100 & 37 & 100 & 55 & 100 \\
\hline
\end{tabular}

Fonte: Inquérito realizado à população da freguesia de Serzedelo entre Julho e Outubro de 2010.

QUADRo XIV - Período de residência na casa actual em Serzedelo por sexo no grupo dos expostos e não expostos.

\begin{tabular}{|c|c|c|c|c|c|c|}
\hline \multicolumn{7}{|c|}{ Grupo dos Expostos } \\
\hline & Masculino & Percentagem & Feminino & Percentagem & Total & Percentagem \\
\hline$<10$ anos & 5 & 8,5 & 7 & 11,9 & 12 & 10,1 \\
\hline De 10 a 20 anos & 18 & 30,5 & 21 & 35,6 & 39 & 33,1 \\
\hline De 21 a 30 anos & 17 & 28,8 & 13 & 22,0 & 30 & 25,4 \\
\hline De 31 a 40 anos & 8 & 13,6 & 6 & 10,2 & 14 & 11,9 \\
\hline 41 e mais anos & 11 & 18,6 & 12 & 23,3 & 23 & 19,5 \\
\hline Total & 59 & 100 & 59 & 100 & 118 & 100 \\
\hline \multicolumn{7}{|c|}{ Grupo dos não Expostos } \\
\hline$<10$ anos & 1 & 5,6 & 9 & 24,3 & 10 & 18,2 \\
\hline De 10 a 20 anos & 3 & 16,7 & 10 & 27,0 & 13 & 23,6 \\
\hline De 21 a 30 anos & 4 & 22,2 & 10 & 27,0 & 14 & 25,5 \\
\hline De 31 a 40 anos & 6 & 33,3 & 2 & 5,4 & 8 & 14,5 \\
\hline 41 e mais anos & 4 & 22,2 & 6 & 16,2 & 10 & 18,2 \\
\hline Total & 18 & 100 & 37 & 100 & 55 & 100 \\
\hline
\end{tabular}

Fonte: Inquérito realizado à população da freguesia de Serzedelo entre Julho e Outubro de 2010.

QUADRo XV - Auto-avaliação do estado de saúde no grupo dos expostos e não expostos

\begin{tabular}{|c|c|c|c|c|}
\hline \multirow{2}{*}{} & \multicolumn{2}{|c|}{ Grupo dos expostos } & \multicolumn{2}{c|}{ Grupo dos não expostos } \\
\cline { 2 - 5 } & Número & Percentagem & Número & Percentagem \\
\hline Mau & 11 & 9,3 & 4 & 50,3 \\
\hline Razoável & 70 & 59,3 & 28 & 40 \\
\hline Bom & 30 & 25,4 & 1 & 1,8 \\
\hline Muito Bom & 7 & 5,9 & 55 & 100 \\
\hline Total & 118 & 100 & 22 & 0 \\
\hline
\end{tabular}

Fonte: Inquérito realizado à população da freguesia de Serzedelo entre Julho e Outubro de 2010. 
de tabaco e de álcool, a dieta e a actividade física, as características da habitação, o acesso a serviços e a recursos comunitários, as redes sociais, os níveis de ansiedade e de stress, entre outras, o que faz com que este indicador seja um dos mais utilizados no estudo das variações em saúde (Nogueira, 2008).

Dos 118 inquiridos no grupo dos expostos, 59,3\% \% avaliou o seu estado de saúde como "razoável", 9,3\% posicionou-se no nível no nível "mau", tendo 31,3\% reportado estados de saúde nos níveis superiores (bom e muito bom). Quanto ao grupo dos não expostos, verificámos que $41,8 \%$ dos inquiridos reportam estados de saúde positivos (níveis bom e muito bom), 50,9\% avalia-o como razoável e 7,3\% reporta estados de saúde no nível mau.

Desta análise sumária, emerge uma diferença considerável na auto-avaliação do estado de saúde entre os grupos expostos e não expostos. No grupo dos indivíduos expostos, não só a percentagem de inquiridos que avalia de forma negativa o estado de saúde é maior do que a encontrada no grupo dos não expostos $(9,3 \%$ $7,3 \%$, respectivamente para expostos e não expostos), como é menor a percentagem daqueles que avaliam a saúde de forma positiva, verificando-se a este nível uma diferença relevante (cerca de 10,5\% mais de inquiridos não expostos com auto-avaliações nos níveis bom e muito bom, comparativamente aos inquiridos não expostos).

Em síntese, os grupos em estudo - expostos e não expostos - diferem em relação a características que podem fazer variar o estado de saúde e as morbilidades experienciadas pelas pessoas. Verificámos variações no género e na idade, no nível socioeconómico, no tempo de residência em Serzedelo e no tempo de permanência na habitação actual entre os inquiridos, em função da exposição, ou não, às linhas de altas tensões. Verificámos também a existência de diferenças no estado de saúde em função dessa mesma exposição. Embora não possamos apontar a existência de uma associação entre as determinantes que estudámos e o estado de saúde, a análise que efectuámos não invalida essa possibilidade, uma vez que se verificaram variações no estado de saúde entre os grupos expostos e não expostos. Como já referimos, pretendemos estudar essa associação com base em modelos de regressão logística, que devem necessariamente ser ajustados para as características demográficas, sociais e geográficas que destacámos neste artigo.

\section{Limitações deste tipo de estudo}

As entidades que podem fornecer dados sobre morbilidade são o Instituto Nacional de Estatística (INE), o Instituto Português de Oncologia (IPO) e os RORENO. Como estudámos a problemática à escala local (freguesia), temos o problema da falta de detalhe dos dados (e.g., ausência de morada ao nível da freguesia). No que se reporta aos dados sobre a mortalidade, os organismos que nos podem fornecer os dados são o INE e a Conservatória do Registo Civil de Guimarães. As limitações subjacentes aos dados publicados, de morbilidade ou de mortalidade, são as seguintes:

-os dados de mortalidade de que necessitamos estão presentes nas Estatísticas da Saúde, publicadas anualmente pelo INE desde 1969, mas, com o avançar dos anos, os dados a que podemos ter acesso são cada vez mais restritos, especialmente no que concerne ao nível de desagregação dos mesmos. Os dados que o INE pode fornecer não estão desagregados até à escala local, ficando-se pela NUTS II e em alguns casos pela NUTS III;

-os dados publicados pelo INE referentes à morbilidade ou que podem ser adquiridos através de pedido (dados disponíveis não publicados), não contemplam o cancro. As Estatísticas da Saúde realizadas e publicadas pelo INE só possuem dados sobre a morbilidade, por exemplo, em relação à tuberculose e ao virús da imunodeficiência humana (VIH) e da síndrome da imunodeficiência adquirida (SIDA);

- no que concerne aos dados da Conservatória do Registo Civil de Guimarães, estes são os que seguem semanalmente para o INE (Lisboa) e que servem de base à publicação das Estatísticas da Saúde e não seria exequível consultá-los no período de tempo de que dispusemos para a realização da presente investigação. Necessitaríamos de alguns anos de trabalho intensivo de consulta dos certificados de óbito na conservatória (que detêm mais informação do que a que é posteriormente publicada nas Estatísticas da Saúde) para podermos tirar alguma ilação substantiva.

A entidade que nos pode fornecer dados mais detalhados sobre a morbilidade por cancro é a RORENO, mas os dados apresentam também algumas limitações. Segundo Maria José BENTO, responsável pelo RORENO, os dados sobre a morbilidade por cancro são bastante incompletos, especialmente no que se refere à morada ou freguesia de residência do indivíduo ao qual foi diagnosticado um cancro. Outro problema referido por aquela responsável, em reunião concretizada no dia 4 de Janeiro de 2010, é o facto de parte dos serviços de saúde privados não colaborarem ou enviarem os seus registos oncológicos incompletos.

Resumindo, os dados publicados sobre a morbilidade e a mortalidade por cancro apresentam várias limitações e são parcos para avaliar a problemática em estudo, sendo um grande handicap para o geógrafo, para quem a componente territorial é fundamental. 


\section{Conclusões}

A problemática seleccionada é complexa, pois a poluição electromagnética é um tipo de poluição invisível, o que "impede" as pessoas de terem um comportamento preventivo, porque, por vezes, é difícil identificar uma fonte de campos electromagnéticos.

Outro factor que aumenta a complexidade e a dificuldade de estudar esta problemática é o facto de estarmos a analisar efeitos na saúde dos indivíduos, sabendo que a saúde é um conceito muito abrangente e que pode ser influenciado por uma variedade de factores individuais, ambientais, sociais e culturais.

Outro facto que importa não esquecer é o de que as doenças mais frequentemente associadas aos efeitos dos campos electromagnéticos na saúde são raras, dificultando, sobremaneira, o estabelecimento de uma correlação ou associação.

Contudo, e à luz das conclusões da monografia da OMS, em 2007, que afirma que devemos pôr em prática o princípio da precaução, a não identificação, até ao presente, de um mecanismo que explique as alterações na saúde dos indivíduos, não elimina a possibilidade de eles se verificarem. Portanto, os responsáveis pelo planeamento e pelo ordenamento do território devem pôr em prática o princípio da precaução e criar corredores que limitem a construção até 100 metros das linhas (limite até ao qual a influência parece ser mais importante), atribuindo a esses corredores a mesma importância que é dada, por exemplo, aos leitos de cheia.

Somos de opinião que as ciências cindínicas deviam dar mais atenção a este tipo específico de risco, porque as áreas próximas das linhas de alta tensão são bacias de risco, existindo o risco de incêndio e de morte, se se concretizar a queda de uma linha, além de todos os restantes riscos equacionados no decurso do presente artigo.

0 presente texto pretendeu ser uma primeira abordagem à problemática do electromagnetismo e da sua influência na saúde das populações, avançando com uma metodologia que não foi ensaiada até ao presente (estudo de expostos e não expostos), diferente da que costuma ser equacionada (estudo de caso-controlo). A dificuldade em obter dados desagregados para a escala de freguesia levou-nos a considerar a realização de um inquérito por entrevista semi-estruturada, que foi finalizado em Dezembro de 2010, tentando complementar o estudo sumário que foi concretizado em 2008 pela ARSN. Estamos cientes de que se trata de um estudo exploratório e essencialmente descritivo, mas que constitui a base necessária para desenvolvermos análises mais aprofundadas e explicativas, que coloquem em evidência a existência de situações de risco e de "injustiça ambiental" em Portugal e o impacte dessas situações e desses riscos na saúde das populações.

\section{Referências bibliográficas}

ARSN (2008) - "Risco de morrer no concelho de Guimarães. Uma análise da mortalidade 1997-2005”, [pdf]. Protocolo disponível: http://portal. arsnorte.min-saude.pt/portal/page/portal/ ARSNorte/Conte\%C3\%BAdos/Sa\%C3\%BAde\%20 P\%C3\%BAblica\%20Conteudos/Risco_de_ Morrer_Guimaraes_relatorio_1997_2005.pdf. [23-03-2010].

DÉoux, S.; Déoux, P. (1996) - "Ecologia é a saúde", Instituto Piaget, Lisboa.

Faugeres, L. (1990) - "La théorie du risque“. Le Risque et la Crise", Foundation for Internacional Studies, Malta.

MACINTYRE, S. (2007) - "Deprivation amplification revisited; or, is it always true that poorer places have poorer access to resources for healthy diets and physical activity?" International Journal of Behavioral Nutrition and Physical Activity, 4 (32) doi: 10.1186/1479-5868-4-3232.

MAUSNer, J.; Kramer, S. (2009) - "Introdução à epidemiologia", Fundação Calouste Gulbenkian, Lisboa.

Nogueira, H. (2008) - "Os lugares e a saúde", Imprensa da Universidade de Coimbra, Coimbra.

NoguelRA, H. (2010) - "Deprivation amplification and health promoting resources in the context $f$ a poor country". Social Science and Medicine, 70, 1381-1385.

Nogueira, H.; Remoaldo, P., (2010), "Olhares geográficos sobre a saúde", Edições Colibri, Lisboa.

Oliveira, A. Gouveia de (2009) - "Bioestatística, epidemiologia e investigação", Lidel, Lisboa.

OMS (1998) - "Campos electromagnéticos e saúde pública". http://193.136.221.5/item/ administracao/project_documentation/ monIT_Ext_Tec_0630_02_FactSheet182.pdf. [21-03-2010].

REN (2010) - Caracterização da rede nacional de transporte para efeitos de acesso à rede em 31 Dezembro de 2009, [pdf]. http://www. centrodeinformacao.ren.pt/PT/publicacoes/ CaracterizacaoRNT/Caracterização\%20da\%20 RNT\%2031-12-2009.pdf. [10-04-2010].

RORENO (2000) - Registos oncológicos da Região Norte 1999-2000, Instituto Português de Oncologia do Porto, Porto.

RORENO (2002) - Registos oncológicos da Região Norte 2001-2002, Instituto Português de Oncologia do Porto, Porto. 
RORENO (2003) - Registos oncológicos da Região Norte 2003, Instituto Português de Oncologia do Porto, Porto.

RORENO (2004) - Registos oncológicos da Região Norte 2004, Instituto Português de Oncologia do Porto, Porto.

RORENO (2005) - Registos oncológicos da Região Norte 2005, Instituto Português de Oncologia do Porto, Porto.
SÁ, J. (2008) - "Campos electromagnéticos de extremamente baixa frequência, saúde pública e linhas de alta tensão". https:// dspace.ist.utl.pt/bitstream/2295/164948/1/ CEMEBF\%20saude\%20publica\%20e\%20linhas\%20 de\%20Alta\%20Tensao.pdf. [21-02-2010].

WHO (2007) - "Extremely low frequency fields. Environmental Health Criteria", Vol. 238, World Health Organization, Geneva. 